\title{
LORA based Biotelemetry System for Large Land Mammals
}

\author{
Karin Cristine Grande ${ }^{1}$, Fausto Fernando Hilario Gomes ${ }^{2}$, Eduardo Lino Santiago ${ }^{3}$, Pedro Miguel \\ Gewer $^{4}$, Victor Hugo Dambrat Bergossi ${ }^{5}$, Bertoldo Schneider Jr ${ }^{6}$ \\ 123456 Federal University of Technology - Paraná, Brazil \\ Karincristine13@gmail.com \\ bertoldo@utfpr.edu.br
}

\begin{abstract}
The best way to understand the environment and its actors is monitoring them. Brazil has the two most biodiversified forests in the planet, the Amazon and the Atlantic forests, a vast field for biotelemetry. Biotelemetry is still made in the most part of the world with obsolete technologies, causing animal stress and demanding a lot of extra field human work. A good biotelemetric system must have quasi-real time, no animal stress, channels for biological, climate, meteorological, and positional data, low power, shorter antenna, and low cost as possible characteristics. It was designed a LORA $®$ technology based animal tracking device, small enough to fit in a collar of a large mammal (e.g., Panthera onca), capable to provide real-time position information and other physiological parameters. Tests was made where a volunteer, with the device rode a bicycle through a large urban area and the real time data, collected by a fixed base, were successfully compared with reference GARMIN GPS $®$ device data. Additionally, several Arduino based circuits for physiological, positional and meteorological data measurements can provide extra information for the biotelemetric system proposed. The system is ready to field biological tests and needs improvement and integration with other GPS, GPRS and UHF technologies.
\end{abstract}

Key words: biodiversified forests, biotelemetric system, quasi-real time, animal tracking, LoRa systems.

\section{Introduction}

Biotelemetry is a technology system that allows to supervise, locate and collect information from forms of life from a distance using radio communication, satellite, GPS, wireless, and others. The relevant data are geographical coordinates (latitude, longitude, altitude, date and time), physiological parameters (heartbeat rate, body temperature, velocity, etc) [1, 2], climatic data (light, temperature, humidity, pressure), and anyone other for study of species in natural (or not) habitat. Biotelemetry is a remote system, by definition, and can collect data from isolated places on the planet.

An important work was made in Minnesota University with the white-tailed deer (Odocoileus virginianus) [3], and it is probably the first animal tracking work ever. Another of the first works observing animals was made in 1960's by Craighead brothers, in Yellowstone
American Park. They studied the behavior of the grey bear (Ursus arctos horribilis) in his habitat $[4,5,6]$. For this, a tracking device was created using an UHF transmitter device in a collar placed in the bear. A team of researchers using three or more antennas localized the animal by goniometry triangulation. The hibernation place and period was discovered in that work. After that many others works with animals was made, opening the way for ecology, animal behavior, and animal routes and habitats research.

When an animal is extinct there is an unbalance in its influence area. This unbalance can promote unbalance in the animal and vegetal spheres including serious environment and economic instability for human being. A lot of species are in the extinction risk and many are the reasons for this. Illegal hunt is the principal, followed by human occupation, natural 
disasters, sicknesses, among others. In the last years humanity could see many extinctions, like the North white rhinoceros (Ceratotherium simum cottoni) declared extinct in march 20 , 2018, after the dead of the last male in Kenya. Its correlated black rhinoceros (Diceros bicornis) was extinct in 2011. These are examples of animals that were extinct by illegal hunt. Others species suffer with this and bad management and bad policies, like the famous Cecil lion, which was killed by an illegal hunter in its sanctuary, the National park of Hwange. In this case, even using a track system, there was no time to save it, because the no-real-time technology did not enable fast reactions. The International Union for Conservation of Nature (IUCN) is the institution that elaborates the red lists of endangered species, showing to the world the problem created by human beings. Animals are in constant movement, searching for environmental resources, food, protection, and mating. This movement can beneficiate the man and the nature by carrying seeds and pollen, or bad things like illness, like the case of the migratory birds. Tracking these animals generates new understanding to prevent and protect, or stimulate, when necessary [2]. Aiming the preservation and conservation of the species, the better understanding of the world and its relation with the man, as well as the sustainability and economic exploration of the natural resources, many scientists had developed several animal tracking technologies.

The biological research depends on the precision of the data collected [7]. Those technologies can be simple system like monitoring by photo machines or complex ones, like real time monitoring [6]. The most used system are those based on very high frequency (VHF) and Ultra high frequency (UHF) bands. Those systems were less expensive and were largely used [8]. They need two components, the transmitter and the receiver. The transmitter is placed next to the animal, fixed by collars, vest, glue, implants, hook, ring, and the receiver is used by the researcher. Usually, this researcher or team need to stay closed the animal, directing the antenna to the right place. This field action could take several hours, or even days for encounter the signal position [9]. This technology had survived till nowadays by using additional technologies like drones [9], or telephone towers, or internet. Another adaptation was made by the University of Wisconsin-Milwaukee scientists, which put tags with transmitters in sturgeon fishes of sea and rivers, using drones to overfly to keep the sturgeon signals [10]. Some systems has no transmission and use a local memory to store data. It is the case of greater animals like monkeys and apes, and these animals need to be captured and their collars removed for the scientists to access the data [11].

Another method uses the sound. Echolocation systems use a source of sound or ultrasound and analyses its reflection, locating or measuring animal trajectories. Acoustic localization is different, because in this case only the animal makes sounds. Those sounds when analyzed can identify the species, localize individuals or even count them (object of studies of our Biomedical Engineering research team in UTFPR). Some teams add radio devices to acoustic localization [12]. In a study with killer whales or orcas (Orcinus orca), in Oregon, USA, it was possible, by passive acoustic observation, using subaquatic sound sensors, to know the area of activity and migration routes of this animals [13].

When the animal is a bird the system must be slim and weightless [7]. Some scientists use tags with memory and (Global position system) GPS embedded, but it is necessary capture the bird to read the data, causing stress in the animals e arising the cost of the research [16]. The use of the GPS is very important for the animal tracking because its high precision data [14]. The problem is that GPS systems has no transmission devices, so it is common to use the Global system for mobile \& General packet radio service (GSM/GPRS) where the telephone services are present. Systems using satellites are very efficient and the great advantage is the global service covering, even over oceans. The Argus service, initiated in 1978, with 12 active satellites over each hemisphere, works like an auxiliary system for animal and ships tracking, and maritime safety $[8,15,16]$. Sometimes there is no Argus satellite over the observed animal, causing a lack of contact which can remain for hours.

The proposed system developed by Biotelemetry team of the Federal University of Technology - Paraná, Curitiba, Brazil, was designed to be a quasi-real time system.

\section{Methods}

The developed system has a LORA RN2903 working with a microcontroller PIC18LF45K22I/PT and a GPS Integrated circuit, like shown in Fig. 1. In Brazil this IC, the same used in Europe, is homologated for $14 \mathrm{~dB}$, differently of the Europe and USA. The program was made with $C$ language and the data is transmitted in ASCIl code, for minimize transmission energy. Some additional systems based on Arduino platform can measure temperature, humidity, 
velocity, light and physiological parameters (heartbeat rates, oxygen saturation, and internal temperature when an implant could be made), working like parallel and auxiliary sensors.

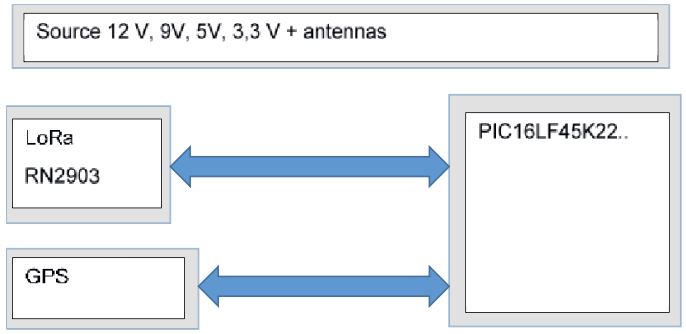

Fig. 1. Block diagram of the tested system. A LoRa RN2903 and an ordinary GPS IC working with a microcontroller PIC18LF45K22-I/P. A battery is used to source the voltages necessaries for the circuit and appropriated common antennas for GPS reception and LoRa Transmission.
For testing the device it was focused in demonstrate its capability of transmit the precise position in bad conditions, i.e., near to the end of life of battery conditions, or when the source of energy is almost depleted. Thus, an area of a big urban park was choice to test the system, using a battery with less than $30 \%$ of charge. The points was processed using the TrackMaker software version 13.9. The software access the satellite photo of the Google Earth shown in Fig. 2.

\section{Results}

The Barigui Park of the Curitiba city in south Brazil was used to test the performance in bad conditions of energy. The mobile part was put in a bicycle basket and a button was pressed to transmit a position. Each position successfully received is marked in Fig. 2 with a circle with a central dot and in Fig. 3 with a diamond. In the same basket, a Garmin GPS reference device model E-trex 30 was programed to keep the way points automatically. The way of the GPS E-trex device is shown in Fig.2 with continuous line.

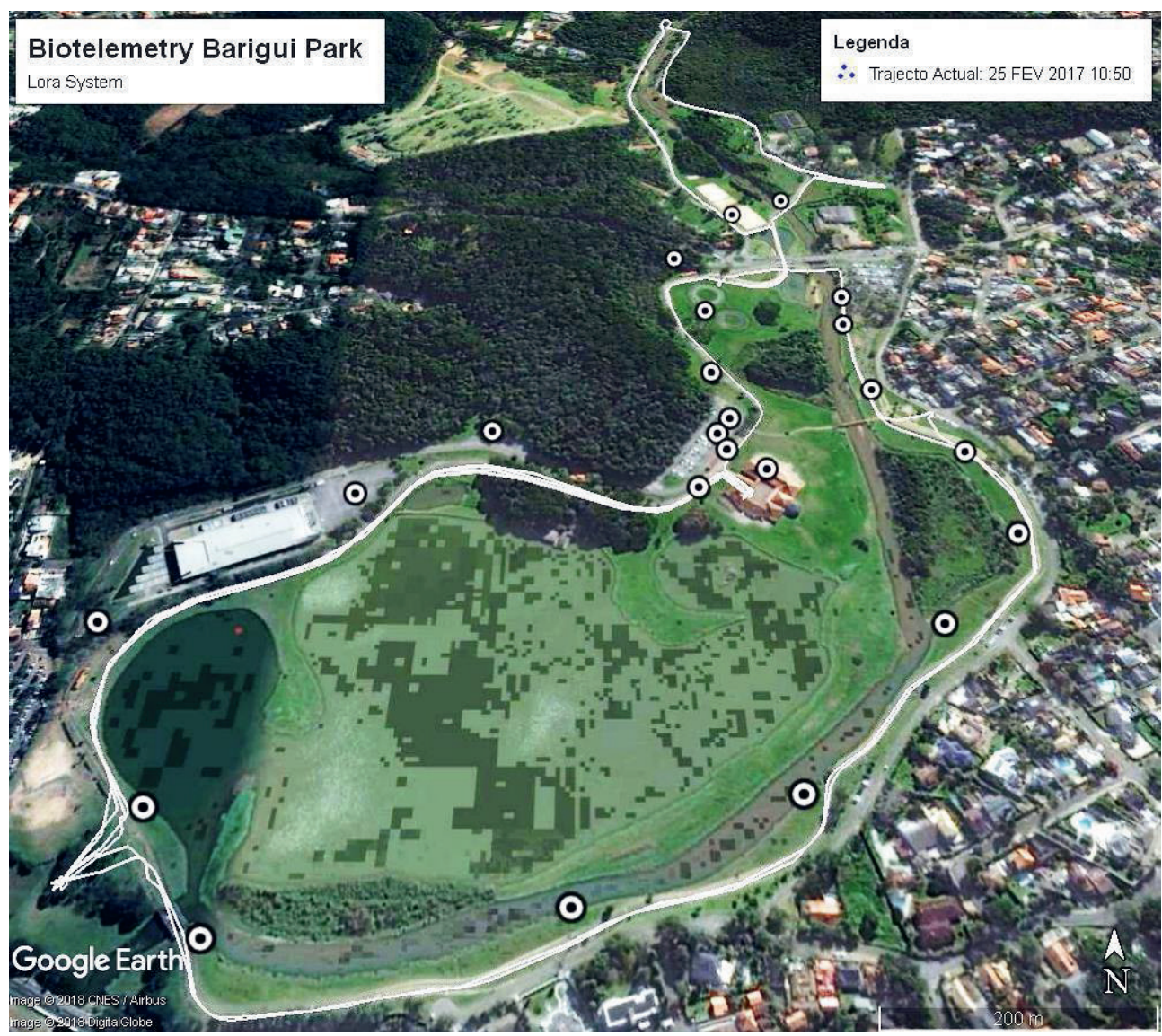

Fig. 2. The continuous line represents the way marked by the GPS E-trex reference device. The circles with a center dot shows the successfully received positions. The photo is a satellite photo, in a non-orthogonal 
perspective, of the Barigui park in Curitiba, South Brazil, license of the Google Earth. The software used for integration of these data was the TrackMaker software version 13.9.

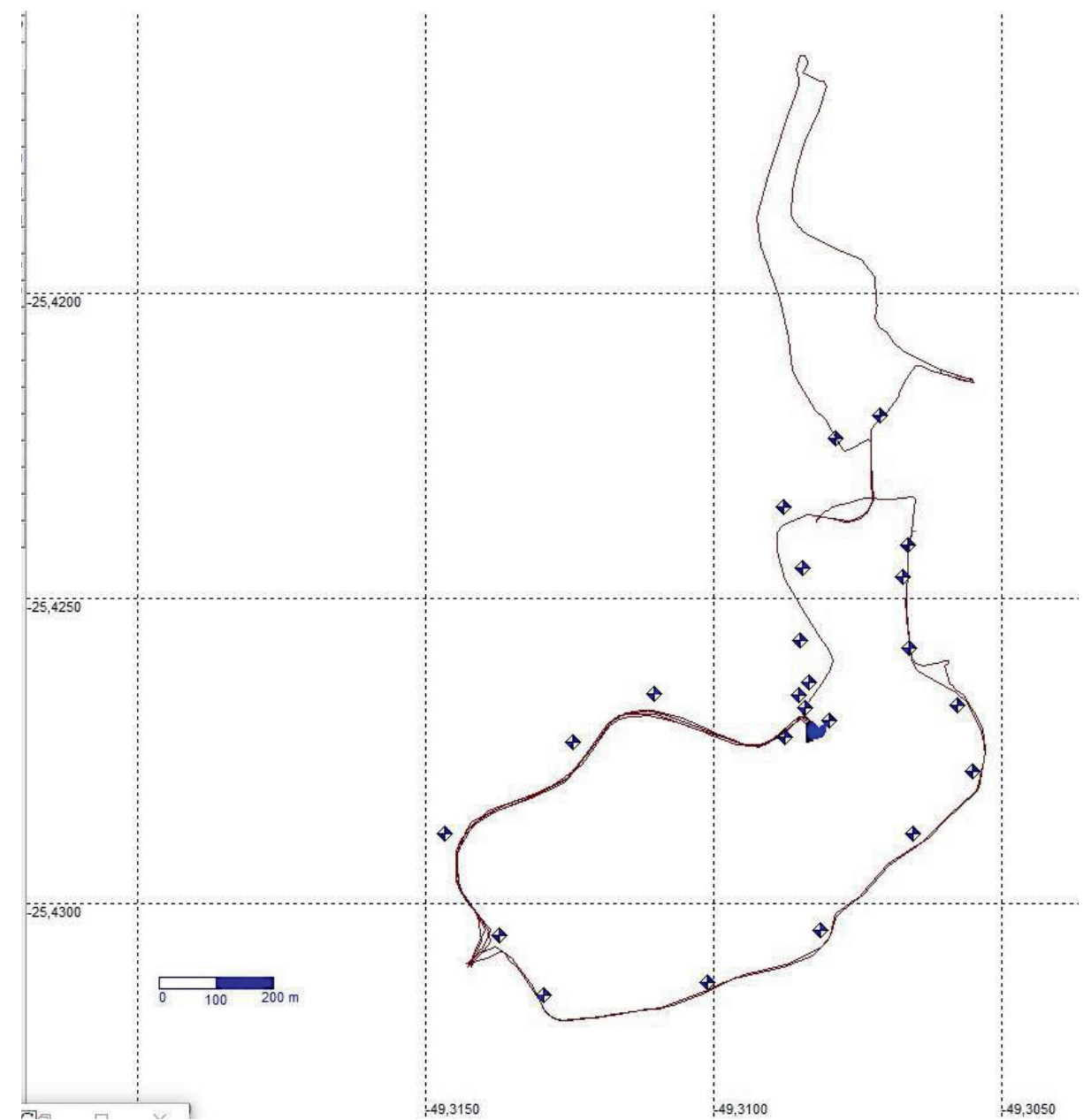

Fig. 3. Image of the TrackMaker software. The continuous line represents the way marked by the GPS E-trex reference device. The diamonds shows the successfully received positions. Orthogonal point of view.

\section{Conclusion and Discussion}

It is possible to note the great error, sometimes near $30 \mathrm{~m}$ in a relative plain terrain. Although this error is not so big for animal tracking application, it is necessary to consider about its fonts. First of all, there is the low battery problem. Our methodology demanded an almost depleted battery. This can account to imprecision of the points. Besides, points farther than $800 \mathrm{~m}$ was not successfully received. In Fig. 2, there would be points in the right upper corner of the figure. This problem is certainly related with battery condition, because tests in plain terrain with full charged battery and the same antennas achieved a distance of $1.8 \mathrm{~km}$ in urban area. Other font of error is the datum used in the GPS integrated with the LoRa circuit. Theorically, the position of a point in the Earth surface depends on the ellipsoid of revolution used to model the curvature of the planet surface. The set of measurements and conditions of this model is called datum in geodesy and cartography [17]. Datum must be configurated for each region of the planet, to enhance accuracy. Generally it is used the WGS84 world standard datum. In Brazil the official datum was changed from the SAD-69 to SIRGAS-2000 in 2005. A little tens of meters of error can be attributed to difference between datums used.

It was used the interchanged ICs NR2903 (American standard) for $915 \mathrm{MHz}$ and the NR2483 replacing the 2904 of the Fig. 1. The frequency used for the data set shown here was the $686 \mathrm{MHz}$, using the NR2483. The proposed device demonstrated appropriated performance to animal tracking purpose and new experiences are made with other technologies and systems, like gateways, GPRS, UHF repeater, as well as the field work with mammals like the guará wolf (Chrysocyon brachyurus) and some kind of wild felines, like the jaguar (Panthera onca). The program of the system was enhanced and now is immune to 
unsuccessful reception and works full automatically. The redesign seeks very low power consumption and lighter device. The microcontroller can be anyone with I2C and enough analogue and digital entries.

\section{Acknowledgements}

The authors would like to thank the support received from the CAPES (Coordination for the Improvement of Higher Level Personnel), the Graduate Program in Electrical and Computer Engineering (CPGEI) and Graduate Program in Biomedical Engineering (PPGEB), both in UTFPR.

\section{References}

[1] V. R. Jain, R. Bagree, A. Kumar \& P. Ranjan. wildCENSE: GPS based animal tracking system. In Intelligent Sensors, Sensor Networks and Information Processing, 2008. ISSNIP 2008. International Conference. Pp. 617-622. (2008). Doi: 10.1109/ISSNIP.2008.4762058

[2] R. Kays, M. C. Crofoot, W. Jetz \& M. Wikelski. Terrestrial animal tracking as an eye on life and planet. Science. V. 348, $\mathrm{n}^{\circ} 6240$, aaa2478. (2015). Doi: 10.1126/Science.aaa2478

[3] J. R. Tester, D. W. Warner, \& W. W. Cochran. A radio-tracking system for studying movements of deer. The Journal of Wildlife Management. Pp. 42-45. (1964). Doi: 0.2307/3797933

[4] J. J. Craighead, \& F. C. Craighead Jr. Grizzly bear-man relationships in Yellowstone National Park. BioScience. V. $21 \mathrm{n}^{\circ}$ 16, pp. 845-857. (1971). Doi: 10.2307/1295811

[5] F. C. Craighead Jr, \& J. J. Craighead. Data on grizzly bear denning activities and behavior obtained by using wildlife telemetry. Bears: Their Biology and Management. Pp. 84-106. (1972). Doi: $10.2307 / 3872573$

[6] C. S. Miller, M. Hebblewhite, J. M. Goodrich \& D. G. Miquelle. Review of research methodologies for tigers: telemetry. Integrative Zoology. V. 5, $\mathrm{n}^{\circ}$ 4, pp. 378-389. (2010). Doi: 10.1111/j.17494877.2010.00216.x

[7] N. Sobajic, J. Gutierrez, R. Kraemer \& M. Krstic. Using wake-up receivers in bird telemetryViability study. In Telecommunication in Modern Satellite, Cable and Broadcasting Services (TELSIKS), 11th International Conference on. V. 2, pp. 530-533. (2013). Doi: 10.1109/TELSKS.2013.6704434

[8] S. Erdogan, T. Shaneyfelt \& A. Honma. Integrated Knowledge Base for Environmental Research. Autonomic and Autonomous Systems and International Conference on Networking and Services ICAS-ICNS 2005. Joint International Conference on. IEEE. Pp. 54-54. (2005). Doi: 10.1145/1095242.1095267
[9] G. A. M. Dos Santos, Z. Barnes, E. Lo, B. Ritoper, L. Nishizaki, X. Tejeda, A. Ke, H. Lin, C. Schurgers, A. Lin \& R. Kastner. Small unmanned aerial vehicle system for wildlife radio collar tracking. In Mobile Ad Hoc and Sensor Systems (MASS), 2014 IEEE 11th International Conference. Pp. 761-766. (2014). Doi: 10.1109/MASS.2014.48

[10] T. R. Consi, J. R. Patzer, B. Moe, S. A. Bingham, \& K. Rockey. An unmanned aerial vehicle for localization of radio-tagged sturgeon: Design and first test results. In OCEANS'15 MTS/IEEE Washington. Pp. 1-10. (2015). Doi: 10.23919/OCEANS.2015.7404448

[11] C. P. Juarez, M. A. Rotundo, W. Berg \& E. Fernández-Duque. Costs and benefits of radiocollaring on the behavior, demography, and conservation of owl monkeys (Aotus azarai) in Formosa, Argentina. International Journal of Primatology. V. 32, n¹, pp. 69-82. (2011). Doi: 10.1007/s10764-010-9437-z

[12] S. Fregosi, H. Klinck, M. Horning, C. P. Costa, D. Mann, K. Sexton, L. A. Hückstädt, D. K. Mellinger \& B. L. Southall An animal-borne active acoustic tag for minimally invasive behavioral response studies on marine mammals. Animal Biotelemetry. V. 4, n¹, pp. 4- 9. (2016). Doi: 10.1186/s40317-016-0101-z

[13] H. Matsumoto, A. Turpin, J. Haxel, C. Meinig, M. Craig, D. Tagawa, H. Klinck \& B. Hanson. A Real-time Acoustic Observing System (RAOS) for killer whales. In oceans 2016 mts/ieee monterey. Pp. 1-6. (2016). Doi: 10.1109/OCEANS.2016.7761032

[14] F. Urbano, F. Cagnacci, C. Calenge, H. Dettki, A. Cameron \& M. Neteler. Wildlife tracking data management: a new vision. Philosophical Transactions of the Royal Society B: Biological Sciences. V. 365, n¹550, pp. 2177-2185. (2010). Doi: $10.1098 /$ rstb.2010.0081

[15] R. Lopez, J. P. Malarde, F. Royer \& P. Gaspar. Improving Argos doppler location using multiplemodel Kalman filtering. IEEE Transactions on Geoscience and Remote Sensing. V. 52, $n^{\circ} 8$, pp. 4744-4755. (2014). Doi: 10.1109/TGRS.2013.2284293

[16] J. M. Martin, G. W. Swenson \& J. T. Bernhard. Methodology for efficiency measurements of electrically small monopoles for animal tracking. IEEE Antennas and Propagation Magazine. V. 51, $\mathrm{n}^{\circ}$ 2. Pp. 39-47. (2009). Doi: 10.1109/MAP.2009.5162015

[17] R. M. Friedmann. Fundamentos de orientação, cartografia e navegação terrestre. Fundamentos de Orientação, Cartografia e Navegação Terrestre. Curitiba: UTFPR ed. (2008). 